\title{
Los derechos sociales en Perú. La influencia de la Constitución mexicana de 1917*
}

Social Rights in Peru. The Influence of the Mexican Constitution of 1917

Miluska Orbegoso Silva**

\begin{abstract}
RESUMEN
En este trabajo abordaremos la importancia e influencia del constitucionalismo mexicano en la construcción del Estado social, especialmente en Perú. La Constitución mexicana de 1917 fue la primera del mundo en recoger los derechos sociales. Ello trajo consigo que las Constituciones latinoamericanas del siglo xx siguieran esta corriente y recogieran un amplio catálogo de derechos sociales, a lo cual no ha sido ajeno el constitucionalismo peruano.
\end{abstract}

PALABRAS CLAVE: DERECHOS SOCIALES, ESTADO SOCial, Constitución, Perú, MÉxico.

\begin{abstract}
In this research work we will address the importance and influence of the Mexican constitutionalism on the construction of the Social State, especially in Peru. The Mexican Constitution of 1917 is constituted as the first Constitution in the world that gathers the so-called social rights and it has fuelled that Latin-American Constitutions of the 20th century continue this trend, gathering a wide catalog of social rights, to which the Peruvian constitutionalism has not been unaffected.
\end{abstract}

KEY WORDS: SOCIAL RIGHTS, SOCIAL State, CONSTITUTION, PERU, MEXICO.

\footnotetext{
*Articulo recibido el 22 de enero de 2016 y aceptado para su publicación el 24 de febrero de 2016.

** Investigadora del Centro de Estudios Jurídico-Politicas (Cijurep) de la Universidad Autónoma de Tlaxcala, México. (orbegososilva@gmail.com).
} 


\section{SUMARIO}

1. Introducción

2. Sobre la naturaleza juridica de los derechos sociales

3. Sobre los derechos sociales en general

4. Naturaleza jurídica

5. Derechos sociales en la Constitución mexicana de 1917

6. Los derechos sociales en Perú

7. Conclusiones

\section{Introducción}

Se han cumplido ya casi cien años de vigencia de la Constitución mexicana de 1917 y su influencia en el constitucionalismo latinoamericano es ampliamente conocida. El juicio de amparo y los derechos sociales recogidos en el mencionado texto constitucional han marcado el contenido de las Constituciones del mundo a partir del siglo xx en adelante. El constitucionalismo peruano no ha escapado a este fenómeno pues ya la Constitución peruana de 1920 fue la primera Constitución de Perú en recoger derechos sociales, lo cual resulta de la expansión que tuvieron estos derechos gracias al constituyente mexicano del diecisiete, primero en recoger los mencionados derechos sociales en su texto constitucional.

Por tanto, resulta lógico pensar que sin la Constitución mexicana de 1917 quizá el constitucionalismo latinoamericano, y en particular el peruano, no habría, aun para 1920, recogido en su norma fundamental unos derechos que son necesarios para el desarrollo, en igualdad de condiciones, de la persona. Ello nos lleva a reflexionar necesariamente sobre la importancia que tiene el reconocimiento de derechos sociales en los textos constitucionales y en particular de su naturaleza jurídica.

En ese sentido, el objeto de estudio de la presente investigación son los derechos sociales remarcando la especial importancia del constitucionalismo social mexicana y de su influencia en el constitucionalismo social del siglo xx, en particular en Perú. Por tanto, para cumplir con el objetivo de nuestra investigación vamos a realizar, primero, un breve análisis de la naturaleza jurídica de los mencionados derechos para posteriormente detenernos en un breve recuento histórico sobre el reconcomiendo de derechos sociales en la Constitución mexicana de 1917 y, por último, la regulación que actualmente tienen en el orden jurídico peruano. 


\section{Sobre la naturaleza jurídica de los derechos sociales}

La idea del Estado social de derecho fue acuñada por Herman Heller en $1929^{1}$ y fue institucionalizada en 1949 en la Ley Fundamental de Bonn, al definir al Estado alemán, en su artículo 20, como "un Estado federal, democrático y social" y, en su artículo 28, como "un Estado democrático y social de derecho".

Sin embargo, su origen es más antiguo que la aparición del término. Éste debemos situarlo en Europa a finales del siglo XIX, ${ }^{2}$ en donde se presentaron una serie de revueltas sociales ${ }^{3}$ protagonizadas por el movimiento obrero en toda Europa. ${ }^{4}$ Quienes demandaban una modificación de las condiciones de vida de los grupos menos favorecidos, debido a que aquello que había sido ganado por los burgueses (que el Estado no interviniese en la vida de los ciudadanos y que sea el mercado y el esfuerzo personal lo que determine la distribución de la riqueza, o como diría Elías Díaz "el individualismo y el abstencionismo estatal) ${ }^{5}$ convirtió al Estado en un "Estado-vigilante nocturno". ${ }^{6}$

La sociedad se había transformado en una sociedad basada en la autodeterminación y donde las diferencias sociales crearon cierta injusticia social. Ello, llevó a los ciudadanos a exigir una intervención estatal, de forma que "los Estados industrializados de la época van tomando conciencia de las necesidades de intervenir de forma activa en la vida económica y social". ${ }^{7}$ La pobreza que

\footnotetext{
${ }^{1}$ La aparición del término la encontramos en el escrito ¿Estado de Derecho o dictadura? del mencionado autor. Cfr. Garcia Pelayo, Manuel, Las transformaciones del Estado contemporáneo, Madrid, Alianza, 1977, p. 16.

${ }^{2}$ Cfr. Cossio Diaz, José Ramón, Estado social y derechos de prestación, Madrid, Centro de Estudios Constitucionales, 1989, p. 32.

${ }^{3}$ Aunque en suma puede decirse que surge de la conjunción entre el pensamiento revolucionario francés con la filosofía alemana. Sotelo, IGNACIO, El Estado Social: antecedentes, origen, desarrollo y declive, Madrid, Trotta, Fundación Alfonso Martín Escudero, 2010, p. 13.

${ }^{4}$ Cfr. Abendroth, Wolfgang, Forsthoff, Ernst y Dohering, Karl, El Estado Social, Madrid, Centro de Estudios Constitucionales, Madrid, 1986, p. 16. En Alemania de la mano del canciller Bismarck y de Lasalle; y de otro lado, en Inglaterra se erige el Estado de Bienestar, como respuesta al incremento de la pobreza, gracias a la participación de grandes economistas como Keynes, quien establece los fundamentos económicos del Estado de Bienestar al proponer la intervención del Estado en la economia (sus cuatro aportaciones: la crítica al laissez-faire; la diferencia entre ahorro en inversión; la utilización óptima de los recursos materiales y humanos; y que la política monetaria marque el tipo de interés adecuado para mantener un alto empleo a lo largo del ciclo) y Beveridge, quien diseña un nuevo sistema de Seguridad Social caracterizado por la generalización a todos los ciudadanos, la extensión de los riesgos protegidos, mayor financiación por parte del Estado y unificación de todos los seguros en uno solo (National Insurence Act de 1911 y los Informes que proclaman como pilares del Estado de bienestar: la seguridad social, el pleno empleo y la paz). Cfr. Sotelo, IGNaCIO, El Estado Social: antecedentes, origen, desarrollo y declive, Madrid, Trotta, Fundación Alfonso Martín Escudero, 2010, pp. 163-167 y 205-220.

${ }^{5}$ Cfr. Diaz, Elias, Estado de Derecho y sociedad democrática, España, Taurus, 1998, p. 103.

${ }^{6}$ Garrorena Morales, Ángel, El Estado español como Estado Social y Democrático de Derecho, Universidad de Murcia, Murcia, 1980, p. 24.

${ }^{7}$ Carmona Cuenca, Encarnación, El Estado Social de Derecho en la Constitución, Consejo Económico y Social, Madrid, 2000, p. 39.
} 
se vivía no era algo nuevo; pero sí, en cambio, la indignación que provocaba el empeño del liberalismo por dejar sólo al mercado la distribución de la riqueza. $^{8}$ De forma que, una vez alcanzado el sufragio universal e instalado el proletariado en el poder legislativo, las clases menos favorecidas comenzaron a demandar mayores prestaciones sociales. ${ }^{9}$

En este sentido, el Estado liberal del siglo XIX se va transformando en el Estado social del siglo xx y es así que se fueron reconociendo derechos como el trabajo y la salud en legislaciones y en algunas Constituciones como la mexicana de 1917, la alemana de Weimar de 1919, y la española de la II República de 1931; y en general, el deber del Estado de disminuir con su intervención la desigualdad social. Ello se consolida en Europa después de la Segunda Guerra Mundial (en la Ley Fundamental de Bonn de 1949 se recoge la fórmula del Estado social y en la italiana sin incluir el término) etapa a la que se denomina "edad de oro del Estado de bienestar". ${ }^{10}$ Todo ello significó una mayor participación del Estado e intervención llegando a convertirse en un Estado incluso con iniciativa empresarial en la economía, con la ya famosa "economía social de mercado". ${ }^{11}$ En los años 70 entra en crisis y quizá la principal causa era la imposibilidad de concebir la libertad con la idea de un Estado plenamente interventor, a lo cual se sumó la crisis fiscal, la ineficacia económica y las distorsiones en el mercado. ${ }^{12}$

Como señala García Pelayo el Estado social significa históricamente el intento de adaptación del Estado tradicional, el Estado liberal burgués, a las condiciones sociales de la civilización industrial y post-industrial. ${ }^{13}$ De forma que, lo que buscaba el Estado era conseguir "un disfrute real y efectivo de todos los derechos fundamentales por el mayor número posible de ciudadanos". ${ }^{14} \mathrm{En}$ un inicio esta nueva política social buscaba remediar las pésimas condiciones vitales de los estratos más desamparados y menesterosos de la población. Sin embargo, la actual política social se extiende a toda la población. Además, no se limita a la "menesterosidad económica" sino que se extiende a otros

${ }^{8} \mathrm{Cfr}$. Sotelo, Ignacio, El Estado Social: antecedentes, origen, desarrollo y declive, Madrid, Trotta, Fundación Alfonso Martín Escudero, 2010.

${ }^{9}$ Cfr. Carmona Cuenca, Encarnación, El Estado Social de Derecho en la Constitución, Consejo Económico y Social, Madrid, 2000, p. 51.

${ }^{10}$ Sotelo, Ignacio, El Estado Social: antecedentes, origen, desarrollo y declive, Madrid, Trotta, Fundación Alfonso Martín Escudero, 2010, p. 230.

${ }^{11}$ Cfr. Aragón Reyes, Manuel, "Artículo 1", en Maria Emilia Casas Baamonde y Miguel Rodríguez-Piñero y Bravo Ferrer (Dirs.), Comentarios a la Constitución Española, Madrid, Fundación Wolters Kluwer, 2008, p. 33.

12 Aragón Reyes, Manuel, "Artículo 1", en María Emilia Casas Baamonde y Miguel Rodríguez-Piñero y Bravo Ferrer (Dirs.), Comentarios a la Constitución Española, Madrid, Fundación Wolters Kluwer, 2008, p. 34.

${ }^{13}$ Garcia Pelayo, Manuel, Las transformaciones del Estado contemporáneo, Madrid, Alianza, 1977, p. 18.

${ }^{14}$ Carmona Cuenca, Encarnación, El Estado Social de Derecho en la Constitución, Madrid Consejo Económico y Social, 2000, p. 73. 
aspectos como la cultura, el esparcimiento, la educación, la defensa del medio ambiente, etcétera, siendo que "la política social sectorial se ha transformado en política social generalizada". ${ }^{15}$

Por otro lado, cabe señalar que respecto al Estado social se ha dicho mucho y muchas veces se ha puesto en tela de juicio su viabilidad. Sin embargo, pese a lo antes señalado, su alcance o contenido es el que trae mayores problemas. En primer lugar, y recordando lo dicho por Aragón respecto al Estado democrático, no puede definirse como una forma de Estado sencillamente porque no lo es; sólo se trata de una modalidad de la forma de Estado democrático. "La cláusula 'social' añadida a ese Estado no afecta la estructura de éste, sino a sus fines. Lo que significa es la asunción del Estado de nuevas tareas que no vienen tampoco a sustituir a las antiguas (seguridad, orden público, defensa) sino a complementarlas". ${ }^{16}$ Esas nuevas tareas consisten en alcanzar una mayor igualdad social. "El Estado social, en suma, no significa un modo especial de "ser", sino una manera de "actuar" por parte del poder público". ${ }^{17}$ Con lo cual se demuestra que lo que se busca, al darle al Estado un carácter de social, es identificar, primero, a qué se obliga el Estado y, segundo, a través de qué actos puede alcanzar esos nuevos objetivos que se ha trazado.

El Estado al incorporar el calificativo de social no cambia sus funciones, es decir, seguirá actuando conforme al principio del Estado democrático y de derecho. Ello supone que la administración aún está sometida al principio de legalidad en la actuación y de respeto de los derechos, por lo que en su búsqueda de igualdad social no puede ir en contra de la Constitución y de los derechos que ésta contiene. Por ejemplo el derecho al libre desarrollo de la personalidad, el cual supone "que cada persona puede y debe trazar por sí misma su propio proyecto vital, sin que el Estado deba interferir salvo para salvaguardar los derechos similares de los demás". ${ }^{18}$

Por otro lado, también se ha cuestionado el carácter de norma jurídica de la cláusula del Estado social debido a que de ella no pueden derivarse pretensiones jurídicas inmediatas. Pero ello debe ser matizado y la doctrina junto a la jurisprudencia han concretado su alcance señalando que el contenido de la cláusula debe ser concretado por el legislador. Asimismo, sirve como un criterio de interpretación; y que existe una interdependencia entre la efectividad jurídica

\footnotetext{
${ }^{15}$ Carmona Cuenca, Encarnación, El Estado Social de Derecho en la Constitución, Madrid, Consejo Económico y Social, 2000, pp. 18-19.

${ }^{16}$ Carmona Cuenca, Encarnación, El Estado Social de Derecho en la Constitución, Madrid, Consejo Económico y Social, 2000.

${ }^{17}$ Carmona Cuenca, Encarnación, El Estado Social de Derecho en la Constitución, Madrid, Consejo Económico y Social, 2000.

${ }^{18}$ Diez Picazo, Luis Maria, Sistema de derechos fundamentales, Navarra, Thomson-Civitas, 2008, p. 71.
} 
de la cláusula y la realidad económica. ${ }^{19}$ Pues es un hecho innegable que la materialización del Estado social depende, entre otras cosas, de la capacidad y solvencia económica de cada Estado.

Asimismo, al tratarse de un principio y no de una regla, ${ }^{20}$ "la cláusula del Estado social, por ella sola, no es título atributivo de competencias estatales. Además, el principio del Estado social no impone, por sí mismo, el establecimiento de órganos determinados, ni exige modalidades específicas de composición y funcionamiento de determinados órganos públicos, aunque ambas posibilidades (...) pueden (...) ser obra del legislador”. ${ }^{21}$ Es sólo un principio orientador de la actuación de los poderes públicos que indica que la actuación administrativa debe estar dirigida a conseguir la reducción de la desigualdad social. En ese sentido, lo que busca el Estado social es la igualdad real. Sin embargo, debido a que mediante la intervención del legislador se otorgan títulos de intervención, especialmente a la Administración Pública, la cláusula del Estado social "opera señalando límites de acción posibles particularmente al legislador, no imponiendo concretos límites en la actuación de los poderes públicos”. ${ }^{22}$ No obstante, su función es legitimadora del Estado respecto de los ciudadanos.

\section{Sobre los derechos sociales en general}

Una de las consecuencias más importantes de que un Estado se califique como social es el reconocimiento a nivel constitucional de los denominados derechos sociales. Dar una definición exacta de los mismos resulta una tarea ardua, además de su propia naturaleza, porque en ellos podemos encontrar distintos contenidos referidos a principios del ordenamiento, prestaciones fácticas, mandatos al legislador, garantías institucionales, entre otros. De modo que, en general, podríamos señalar que "hacen referencia a situaciones en las que un sujeto necesita de la colaboración de otros; se concretan en prestaciones". ${ }^{23}$ Asimismo,

\footnotetext{
${ }^{19}$ Aragón Reyes, Manuel, "Artículo 1", en María Emilia Casas Baamonde y Miguel Rodríguez-Piñero y Bravo Ferrer (Dirs.), Comentarios a la Constitución Española, Madrid, Fundación Wolters Kluwer, 2008, p. 192.

${ }^{20}$ Cfr. Aragón Reyes, Manuel, Estudios de Derecho Constitucional, Madrid, Centro de Estudios Políticos y Constitucionales, Madrid, 2009, p. 34. Las reglas y los principios son normas porque ambos dicen lo que debe ser. Los principios son mandatos de optimización (ordenan que algo sea realizado en la medida de lo posible y se pueden cumplir gradualmente) y las reglas, son normas que son cumplidas o no. ALEXY, RoBERT, Teoría de los derechos fundamentales, Madrid, Centro de estudios políticos y constitucionales, 2007, p. 64.

${ }^{21}$ Aragón Reyes, Manuel, "Artículo 1", en María Emilia Casas Baamonde y Miguel Rodríguez-Piñero y Bravo Ferrer (Dirs.), Comentarios a la Constitución Española, Madrid, Fundación Wolters Kluwer, 2008, p. 35.

${ }^{22}$ Fernández López, Maria Fernanda, "Artículo 9.2. La igualdad real" en María Emilia Casas Baamonde, y Miguel RodríguezPiñero y Bravo Ferrer, (Dirs.), Comentarios a la Constitución Española, Madrid, Fundación Wolters Kluwer, 2008, p. 140. ${ }^{23}$ Trujillo Pérez, Isabel, "La discutida juridicidad de los derechos sociales", Persona y Derecho, No. 45, Universidad de Navarra, 2001, p. 263.
} 
pueden calificarse como derechos que se inspiran en la idea de igualdad material y justicia distributiva. Son componentes esenciales de un Estado que se califica como social y democrático de derecho, y de un Estado impelido a intervenir para brindar las medidas correctoras y redistribuidoras que considere necesarias para que los ciudadanos tengan una existencia conforme a la dignidad. ${ }^{24}$

Asimismo, siempre que hablemos de derechos sociales vamos a encontrar dos elementos o constantes: de un lado, el reconocimiento de prestaciones a cargo del Estado y de otro, la aceptación del valor igualdad como finalidad. Por ello, según Cossío, lo correcto sería referirnos a ellos como derechos de igualdad o derechos de prestación, dependiendo de la dimensión a que nos queramos referir. ${ }^{25}$

Por otro lado, centrándonos en el caso de los derechos sociales con contenido prestacional, señala Alexy ${ }^{26}$ que un derecho a prestaciones es todo derecho a una acción positiva por parte del Estado. Entre ellas se incluyen desde la protección del individuo frente a otros, como el derecho penal, las normas de organización, hasta prestaciones en dinero o bienes. Es decir que se incluyen tanto prestaciones fácticas como normativas. Asimismo, señala que estos derechos se dividen en derechos de protección, ${ }^{27}$ derechos a organización y procedimiento ${ }^{28}$ y derechos a prestaciones en sentido estricto. ${ }^{29}$

\footnotetext{
${ }^{24}$ Porras Ramirez, José Maria, "Caracterización y garantía de los derechos de prestación en el Estado constitucional" en Francisco Balaguer Callejón, (Coord.), Derecho Constitucional y Cultura. Estudios en homenaje a Peter Häberle, Madrid, Tecnos, 2004, pp. 661-662.

${ }^{25}$ Cossio Diaz, José Ramón, Estado social y derechos de prestación, Madrid, Centro de Estudios Constitucionales, 1989, p. 46.

${ }^{26}$ Conforme a la clasificación realizada por Alexy, los derechos pueden dividirse en derechos a algo, libertades y competencias. Dentro de los primeros, podemos encontrar una clasificación de los derechos que los divide en derechos a acciones negativas por parte del Estado (llamados también derechos de defensa) y derechos a acciones positivas (o prestacionales). Estos últimos, desde un punto de vista amplio, son "la contrapartida exacta del concepto de derecho de defensa, bajo el que cae todo derecho a una acción negativa, es decir, a una omisión por parte del Estado"; y se dividen, en aquellos cuyo objeto es una acción fáctica, de aquellos que implican una acción normativa. Los primeros, son derechos prestacionales en sentido estricto; mientras que, los segundos, pueden serlo en sentido amplio. Cfr. ALEXY, RoBerT, Teoría de los derechos fundamentales, Madrid, Centro de estudios políticos y constitucionales, 2007, pp. 163 y ss. ${ }^{27}$ Son "los derechos del titular de derecho fundamental frente al Estado para que éste lo proteja de intervenciones de terceros". Su objeto es amplio, y va desde la protección contra el homicidio hasta la protección frente a los peligros generados por el uso de la energía atómica. Asimismo, las acciones dirigidas a la protección, también son diversas y pueden ser judiciales, administrativas u otras. Por otro lado, resalta que deben diferenciarse de los derechos de defensa con los que podrían confundirse pues ambos suponen una omisión de interferencias; sin embargo, "el primero es un derecho frente al Estado a que éste omita intervenciones; el segundo, un derecho frente al Estado para que éste se encargue de que terceros omitan intervenciones". Cfr. ALEXY, RoBERT, Teoría de los derechos fundamentales, Madrid, Centro de estudios políticos y constitucionales, 2007, pp. 398-404.

${ }^{28}$ Los cuales, tienen por finalidad la realización y aseguramiento de los derechos fundamentales. Al respecto, señala Alexy que la idea que los une es el concepto de procedimiento, los cuales, "son sistemas de reglas y/o principios para la obtención de un resultado". Cfr. Alexy, Robert, Teoría de los derechos fundamentales, Madrid, Centro de estudios politicos y constitucionales, 2007, pp. 163 y ss, p. 419.

${ }^{29} \mathrm{Cfr}$. AleXY, Robert, Teoría de los derechos fundamentales, Madrid, Centro de estudios políticos y constitucionales, 2007, pp. 391-393.
} 
Estos últimos, los derechos a prestaciones en sentido estricto, son derechos del individuo frente al Estado a algo que -si el individuo poseyera medios financieros suficientes y si encontrase en el mercado una oferta adecuadapodría obtenerlo también de particulares. Estos derechos pueden clasificarse según generen derechos subjetivos u obligaciones objetivas para el Estado, según sean derechos definitivos o prima facie, y según vinculen o no (denominados también derechos programáticos). ${ }^{30}$

\section{Naturaleza jurídica}

Es necesario precisar: que los derechos sociales requieran de desarrollo legislativo no es lo que evita que sean considerados como verdaderos derechos fundamentales, sino que dependan de un desarrollo posterior para que jurídicamente existan. Esto es, para que sean directamente reclamables en sede judicial como cualquier derecho fundamental.

En ese sentido, debemos señalar que "la aplicabilidad directa del derecho no significa autosuficiencia del mismo para alcanzar su eficacia propia sino la preexistencia del derecho mismo a la intervención del legislador". Esto es, que los derechos fundamentales en general, aunque necesiten de un mínimo desarrollo legal para que materialmente podamos ejercerlos (por ejemplo que exista un sistema electoral regulado para ejercer el derecho al voto), no significa que no puedan ser directamente reclamados. En el caso de los derechos sociales, la necesidad de intervención del legislador en necesaria para la propia efectividad del derecho.

La aplicabilidad directa ya da el perfil propio del derecho fundamental y significa que el derecho, pese a que necesite ser desarrollado por el legislador para que alcancen plenitud y eficacia, éste no puede suponer una desconfiguración del mismo sin incurrir en inconstitucionalidad, pues vulnerará el contenido esencial, ${ }^{31}$ ya que éste preexiste a la ley. Por ello, sólo los derechos fundamentales podrán ser exigidos directamente ante los tribunales no sólo de acuerdo a lo que las leyes desarrollen sino incluso en contra de ellas o cuando ellas falten. Sólo serán fundamentales aquellos derechos resistentes en su contenido esencial a la acción legislativa.

Por otro lado, que los derechos sociales no generan inmediatamente un derecho subjetivo no significa que carezcan de valor normativo. Esto es, "de la cualidad que acompaña a toda norma, y que su alcance se reduce, en

\footnotetext{
${ }^{30} \mathrm{Cfr}$. Alexy, Robert, Teoría de los derechos fundamentales, Madrid, Centro de estudios políticos y constitucionales, 2007, pp. 443-444.

${ }^{31}$ Cfr. Ibidem, p. 25.
} 
consecuencia, al de una mera declaración constitucional de aspiraciones o principios". ${ }^{32} \mathrm{Al}$ respecto, primero debemos mencionar que tienen un valor hermenéutico $\mathrm{y}$, por tanto, vinculan a autoridades en la interpretación del entero ordenamiento jurídico. Segundo: aunque los derechos sociales por sí solos "no pueden fundamentar una pretensión jurídica inmediata, sí pueden hacerlo, en cambio, en la medida en que concurra con otros preceptos para determinar su auténtico contenido y alcance". ${ }^{33}$ Tercero: que en el ámbito del recurso de inconstitucionalidad de la ley, éste "alcanza su máximo nivel de eficacia", pues "se constituye, a fin de cuentas, en fundamento de derecho sobre el que soportar suficientemente el enjuiciamiento de la constitucionalidad o inconstitucionalidad de la ley [...] cuya anulación se pretenda”. ${ }^{34}$ Además tienen cierta "eficacia positiva", ${ }^{35}$ pues aunque los jueces constitucionales no puedan vincular al legislador a producir el derecho que haga reales las expectativas constitucionales, pues ello corresponde a las mayorías parlamentarias, los jueces constitucionales podrían, por ejemplo, dar recomendaciones o declarar las inconstitucionalidad de determinadas conductas. ${ }^{36}$

Por último, es necesario mencionar brevemente la postura Pietro Sanchís, quien sí reconoce una dimensión subjetiva a los derechos sociales. Al respecto, señala este autor que la exigencia de desarrollo legislativo "no impide que pueda apreciarse en ellos una dimensión subjetiva". ${ }^{37}$ Justifica su postura, primero, en que "la intervención del legislador es necesaria para articular derechos subjetivos accionables ante los tribunales y sólo conveniente para perfilar los contornos de unos derechos que ya existen en y desde la Constitución”; y en segundo lugar, en que el desarrollo legislativo es también imprescindible en otros muchos derechos fundamentales. Señala que no sólo pueden ser justiciables ante el Tribunal Constitucional por medio del recurso y la cuestión de inconstitucionalidad, sino también a través del amparo. Reconoce que esa interpretación puede ser un poco tortuosa más no imposible. ${ }^{38}$

\footnotetext{
32 Garrorena Morales, Ángel, El Estado español como Estado Social y Democrático de Derecho, Universidad de Murcia, Murcia, 1980, p. 67.

${ }^{33}$ Garrorena Morales, Ángel, El Estado español como Estado Social y Democrático de Derecho, Universidad de Murcia, Murcia, 1980, p. 70.

${ }^{34}$ Garrorena Morales, Ángel, El Estado español como Estado Social y Democrático de Derecho, Universidad de Murcia, Murcia, 1980, p. 71.

35 Garrorena Morales, Ángel, El Estado español como Estado Social y Democrático de Derecho, Universidad de Murcia, Murcia, 1980.

${ }^{36}$ Cfr. Garrorena Morales, Ángel, El Estado español como Estado Social y Democrático de Derecho, Universidad de Murcia, Murcia, 1980, pp. 72-73.

${ }^{37}$ Prieto Sanchis, Luis, "Los derechos sociales y el principio de igualdad material", Revista del centro de estudios constitucionales, No. 22, septiembre-diciembre, 1995, p. 45.

${ }_{38}$ Prieto Sanchis, LuIs, "Los derechos sociales y el principio de igualdad material", Revista del centro de estudios constitucionales, No. 22, septiembre-diciembre, 1995, p. 45.
} 
Creemos que esta postura basa sus fundamentos en el carácter normativo de la Constitución, mas no en la naturaleza jurídica de los derechos sociales, los cuales, desde nuestro punto de vista, son derechos de configuración legal por las razones antes mencionadas. Los derechos sociales, al estar regulados en la Constitución, tienen una eficacia especifica. Sin embargo, hay dos grandes posturas que se dividen según se niegue o acepte su eficacia.

La tesis que niega eficacia a los derechos sociales fundamenta su postura en que estos principios no pueden ser invocados ante los tribunales y que, por tanto, no vinculan a los poderes públicos. Su estatus es meramente retórico; lo perderán al ser desarrollados por el legislador, es decir, fuera de la Constitución. Como señala Garrido Falla, defensor de esta tesis, un precepto, haya sido incluido en la Constitución o en una ley, no lo convierte en norma jurídica sino que debe tener "estructura lógica de norma jurídica" y que lo demás es pura retórica jurídica. ${ }^{39}$ Ello, desde nuestro punto de vista, no es correcto, pues con la sólo lectura de la Constitución podemos ver que muchas de sus disposiciones, de las cuales no dudamos su carácter de vinculante, no gozan de la mencionada "estructura lógica de norma jurídica”.

Una segunda postura o tesis, que es mayoritaria y compartimos, admite la eficacia jurídica de los derechos sociales. Se fundamenta en el principio normativo y de eficacia directa de la Constitución, por el cual ésta obliga a todos los poderes públicos y ciudadanos en todo su contenido..$^{40}$ De este modo, podemos afirmar que los denominados derechos sociales contenidos en la Constitución sí producen efectos jurídicos y vinculan a los poderes: ${ }^{41}$ al legislador, sobre todo, pues en sus manos recae la labor de desarrollarlos a través de leyes, para que así puedan ser exigibles judicialmente. También le sirven como parámetros de actuación, e incluso suponen para él una "línea de conducta de la que no pueden apartarse". Estos derechos concretan el carácter social del Estado. ${ }^{42} \mathrm{Al}$ Gobierno, al ejercer también funciones legislativas, y en la mera aplicación del ordenamiento, tomando en cuenta su sometimiento al principio de legalidad; al Poder Judicial, al administrar justicia e interpretar las leyes conforme a la Constitución; y al Tribunal Constitucional, al interpretar la Constitución y al analizar la constitucionalidad de las normas. ${ }^{43}$

${ }^{39}$ Garrido Falla, Fernando, Comentarios a la Constitución, Madrid, Civitas, 1980, p. 590.

${ }^{40}$ Cfr. Garcia de Enterria, Eduardo, "La Constitución como norma jurídica", Revista de Administración Pública, No. 100-102, pp. 394-395; Diez Picazo, LuIs Marí, Sistema de derechos fundamentales, Navarra, Thomson-Civitas, Navarra, 2008, p. 58.

${ }^{41}$ Cfr. Pérez Royo, Javier, "Estado Social de Derecho" en Manuel Aragón Reyes (Dir.), Temas básicos de Derecho Constitucional, tomo I, Madrid, Civitas - Thomson Reuters, 2011, p. 193; Parejo Alfonso, Luciano, Estado Social y Administración Pública, Madrid, Civitas, 1983, p. 87, refiriéndose a los principios rectores como "criterios materiales vinculantes para el legislador o, en su caso, para la Administración".

${ }^{42}$ Lucas Verdú, Pablo, La lucha por el Estado de Derecho, Bolonia, Publicaciones del Real Colegio de España, 1975, p. 69.

${ }^{43}$ Cfr. Cossio Diaz, José Ramón, Estado social y derechos de prestación, Madrid, Centro de Estudios Constitucionales, 
Por tanto, podemos concluir que aunque los derechos sociales no se configuren como derechos fundamentales, al estar previstos en la Constitución tienen eficacia y vinculan tanto a gobernantes como a gobernados, aunque ésta no sea directa en sede judicial.

\section{Derechos sociales en la Constitución mexicana de 1917}

En primer lugar, es menester señalar que referirnos a los derechos sociales en México significa a su vez referirnos a la Revolución mexicana. Si bien ésta tuvo un origen político, que no es otro que acabar con la dictadura del general Porfirio Díaz, la existencia de manifiestas injusticias de carácter social tuvo como importante consecuencia que el constituyente de 1917 recogiera, en no otro, que en su texto constitucional, las reivindicaciones de este tipo de derechos.

En ese sentido, la Constitución mexicana de 1917 es resultado de un movimiento social, pues ésta recogió los ideales de la Revolución al buscar una mayor justicia social e igualdad material. Por tanto, "se podría afirmar que la Revolución se hizo Constitución y en vista de ello, esta última debe interpretarse de acuerdo a los antecedentes, supuestos, ideales, programas, etc. de la Revolución y no por sus presupuestos jurídicos". ${ }^{44}$

La Constitución política de los Estados Unidos Mexicanos de 1917 es, sin lugar a dudas, la primera Constitución social del mundo. Hasta antes, el constitucionalismo imperante de la época sólo reconocía la existencia de una parte denominada hasta hoy en día como dogmática, pero referida únicamente a los derechos fundamentales, principalmente de libertad. Los cuales el Estado debía garantizar y respetar mediante acciones negativas, esto es, de no vulneración y de no intervención, como lo mandan los postulados esenciales del Estado de derecho, claro está, salvo causas proporcionalmente justificadas.

Como resulta evidente de lo anteriormente expuesto, la Constitución mexicana anterior, la de 1857, no recogía un catálogo de derechos sociales. Sin embargo, existían dos ideologías predominantes entre los constituyentes de 1917: la de aquellos que querían una reforma de la Constitución de 1857 y la de los más progresistas, que buscaban la sustitución de ese texto, pues estaban convencidos que se habían dejado de lado temas de suma importancia como los derechos sociales, en particular, los de índole laboral y agrario. En ese orden de ideas, "[su] nota más característica (...) consiste en que fue la primera en

\footnotetext{
1989, pp. 262-268.

${ }^{44}$ Cossio Diaz, José Ramón, "Los derechos sociales como normas programáticas y la comprensión política de la Constitución", en Ochenta años de vida constitucional en México, México, UnAM, Instituto de Investigaciones Jurídicas, 1998, pp. 300-301.
} 
incorporar notas de contenido social. La respectiva Comisión de Constitución del Congreso Constituyente de 1916-1917 aceptó adicionar al proyecto del artículo $5^{\circ}$ que contenía la idea de la libertad de trabajo, los principios -que tres diputados constituyentes le habían propuesto- de la jornada máxima de ocho horas, el descanso semanal, la prohibición de trabajo nocturno para mujeres y niños". ${ }^{45}$

Por tanto, la Constitución del diecisiete incorpora artículos fundamentales como, por ejemplo, el artículo 3, referido a la educación pública, gratuita, laica y obligatoria; el artículo 27, a la cuestión agraria; y los artículos 5 y 123, al trabajo y la previsión social. El artículo 5 recoge el derecho a una remuneración justa y el artículo 123 garantizó un salario mínimo así como una jornada laboral de ocho horas, descanso semanal, participación en las utilidades de las empresas, el derecho al trabajo y de huelga. De modo que, podemos concluir diciendo que por vez primera un poder constituyente incorporó a una Constitución política los derechos sociales, en particular, del pueblo mexicano. ${ }^{46}$

$\mathrm{Al}$ respecto, resulta necesario hacer algunas precisiones. En primer lugar, que más que el reconocimiento constitucional de una nueva función u obligación a cargo del Estado, lo que se buscaba era dar cobertura a los derechos de grupos sociales tradicionalmente marginados, trabajadores y campesinos, que fueron quienes habían alimentado los movimientos revolucionarios de las primeras décadas del siglo xx y que constituian la base social indispensable para la legitimación de los poderes públicos. Por lo cual, el reconocimiento de unos derechos específicos de estos grupos sociales resultaba una exigencia fundamental para la continuidad del nuevo Gobierno y en especial, de su legitimación.

En segundo lugar, debemos señalar que la Carta de 1917 recoge derechos sociales, no como exigencia de prestaciones a cargo del Estado como hoy los entendemos, sino como una suerte de limitaciones en materia laboral y agraria a los particulares, salvo el derecho a la educación gratuita recogida en su original artículo 3. Ello con la finalidad de proteger a grupos más vulnerables como niños, trabajadores, jornaleros. ${ }^{47}$ Señala Cossío, en este sentido, que la definición que se tenía de derechos sociales era "aquellas normas constitucio-

${ }^{45}$ Carpizo, Jorge y Carbonell, Miguel, Derecho Constitucional, enciclopedia jurídica mexicana, tomo 8, México, Porrúa - UNAM, 2002, pp. 9-10.

${ }^{46}$ En enmiendas posteriores, se recogieron los derechos de protección a la salud y a la vivienda decorosa, siendo su titular la familia, medio ambiente adecuado, acceso a la cultura, y el derecho a la alimentación y el derecho a la educación. No obstante, la protección de la salud ya era una preocupación del Congreso Constituyente mexicano de 1916-1917, en donde se estableció la salud de los trabajadores como un bien que debían cuidar los patrones y un Consejo General de Salubridad.

${ }^{47}$ Cfr. Cruz Parcero, Juan Antonio, "Los derechos sociales como técnica de protección jurídica" en Miguel Carbonell (Comp.), Derechos sociales y derechos de las minorías, México, Instituto de Investigaciones Jurídicas, México, 2000, p. 88. 
nales que: primero, se hubieran elaborado en contraposición a los contenidos de la Constitución de 1857; segundo, que fueran expresión directa de los postulados de la Revolución de 1910; tercero, que le confirieran atribuciones a los órganos del Estado para imponer obligaciones a cierto tipo de particulares; cuarto, que no le imponían obligaciones directa de carácter patrimonial a los propios órganos estatales". ${ }^{48}$

Ello no es óbice para menguar la importancia del constitucionalismo mexicano en la construcción del Estado social. Sin embargo, como ya sabemos, es en los textos constitucionales promulgados después de la Segunda Guerra Mundial que se observa la consagración constitucional de todo un entramado jurídico, un verdadero cambio de paradigma constitucional en lo que respecta a los derechos sociales y a su verdadera naturaleza; y es entonces cuando el Estado social se consolida, siendo a partir de ese momento cuando comienza un importante proceso de expansión, tanto desde el punto de vista de sus contenidos como desde una perspectiva geográfica, al incrementarse el número de países que intentan adaptarse a sus principios. ${ }^{49}$

\section{Los derechos sociales en Perú}

En el caso peruano, la Carta de 1920 es la primera Constitución que recoge derechos sociales en su título IV denominado garantías sociales, directamente influido por la Constitución mexicana de 1917. Sin embargo, el exhaustivo catálogo de estos derechos apareció por primera vez en la Constitución peruana de 1979 por influencia de la Constitución española de 1978 y los tratados internacionales en materia de derechos humanos, en particular, el Pacto de Derechos Económicos, Sociales y Culturales de las Naciones Unidas. Por tanto, sólo a partir de la Carta de 1993 el Tribunal Constitucional peruano empezó a desarrollar su contenido.

Así, en palabras del Tribunal Constitucional peruano, los derechos sociales son aquellas "facultades tuitivas dirigidas a favorecer a aquellos grupos humanos con características accidentales diferenciadas con relación a otros por factores culturales, o que se encuentran en situación de desventaja por razones económico-sociales, es decir, con una posición o ubicación depreciada en sus

\footnotetext{
${ }^{48}$ Cossio Diaz, José Ramón, "Los derechos sociales como normas programáticas y la comprensión política de la Constitución", en Ochenta años de vida constitucional en México, México, UNAM, Instituto de Investigaciones Jurídicas, 1998, p. 309.

${ }^{49} \mathrm{Cfr}$. Ochando Claramunt, Carlos, El Estado del bienestar. Objetivos, métodos y teorías explicativas, Barcelona, Ariel, 1999, pp. 32-33.
} 
estándares de vida, no acordes con la dignidad humana". ${ }^{50} \mathrm{Y}$ con relación a su carácter social, nos dice que como principios que sustentan y justifican al Estado peruano requieren "de dos aspectos básicos: la existencia de condiciones materiales para alcanzar sus presupuestos, lo que exige una relación directa con las posibilidades reales y objetivas del Estado y con una participación activa de los ciudadanos en el quehacer estatal; y la identificación del Estado con los fines de su contenido social, de forma tal que pueda evaluar, con criterio prudente, tanto los contextos que justifiquen su accionar como su abstención, evitando tornarse en obstáculo para el desarrollo social". ${ }^{51}$

En ese orden de ideas, los derechos sociales son algo así como una especie de "derechos cenicienta", pues requieren de un hada madrina (el Estado) para poder realizarlos. ${ }^{52}$ En ese sentido, uno de los grandes problemas que también se originan en el caso peruano, cuando hablamos de derechos sociales, es el de su justiciabilidad.

$\mathrm{Al}$ respecto, en primer lugar, es menester señalar en el ordenamiento jurídico peruano existe un Código Procesal Constitucional, el cual regula el ejercicio de las acciones constitucionales que reconoce la Constitución de 1993 en su artículo 200. En particular, respecto de los derechos sociales, el proceso idóneo para su protección jurisdiccional sería el juicio de amparo. En ese sentido, el artículo 37 de este Código establece una lista de derechos protegidos por esta garantía: el derecho al trabajo (inciso 10), sindicación, negociación colectiva y huelga (inciso 11), educación (inciso 17), seguridad social (inciso 19), remuneración y pensión (inciso 20), libertad de cátedra (inciso 21), y salud (inciso 24). Se trata de una lista abierta y no cerrada. El mismo artículo dispone que el amparo procede en defensa de "los demás que la Constitución reconoce".

No obstante, la undécima disposición final y transitoria de la Constitución peruana de 1993 establece que "las disposiciones de la Constitución que exijan nuevos o mayores gastos públicos se aplican progresivamente”. Esto se ha entendido de aplicación para el caso particular de los derechos sociales, los cuales requieren para su realización de actuaciones positivas por parte del Estado que se traducen en prestaciones y que por lo tanto requieren de recursos económicos.

En ese sentido, debemos afirmar que los derechos sociales, en el caso peruano, no son derechos subjetivos que el individuo pueda hacer valer ante los

\footnotetext{
${ }^{50} \mathrm{Cfr}$. Expediente No. 2945-2003-AA/TC (Fundamento jurídico 10).

${ }^{51}$ Cf. el expediente 0008-2003.Al/TC (Fundamento jurídico 4.1b).

52 Hakansson Nieto, Carlos, "Los derechos sociales en la constitución peruana. Elementos para una aproximación al reconocimiento y vigencia de los derechos sociales en el marco iberoamericano", Persona y derecho: revista de fundamentación de las instituciones jurídicas y de derechos humanos, No. 66-67, 2012, p. 30.
} 
tribunales ordinarios o ante el Tribunal Constitucional directamente a través del juicio de amparo. No podríamos decir, por ejemplo, que si hiciera falta la construcción de un hospital en una zona determinada se podría demandar al Estado para que edificara uno de manera inmediata. Al respecto, debemos aceptar como una realidad innegable que la realización de los derechos sociales depende de los recursos económicos del Estado y de cómo los administra. Sin embargo, ello no significa que amparado en la onceava disposición final y transitoria, el Estado pueda dejar de cumplir con esta alta misión que se le ha encomendado desde la Constitución: reducir la igual material y desarrollar plenamente los derechos sociales, en la medida de sus posibilidades.

Por tanto, si tomamos como base el artículo 45 de la Constitución peruana que remarca la vinculación de todos los poderes públicos a la Constitución y del principio de normatividad, podemos afirmar que los poderes públicos se encuentran sometidos a todas y cada una de las disposiciones de la Constitución, entre ellas los derechos sociales. De modo que corresponde al Ejecutivo diseñar todas las políticas públicas destinadas a la plena realización de los derechos sociales. Con base en ello, el Legislativo debe aprobar un presupuesto que contemple estos objetivos y a los jueces ordinarios, magistrados del Tribunal Constitucional y, finalmente, a la Corte Interamericana de Derechos Humanos, garantizar en sede judicial la igualdad material y la plena vigencia de los derechos sociales.

En este sentido, La resolución del Tribunal Constitucional peruano 20162004-AA/TC resulta de especial interés. Por primera vez, el máximo intérprete de la Constitución declaró fundada una acción de amparo, ordenando que se considere al agraviado, en su derecho a la vida:

En el grupo de pacientes que recibirían tratamiento integral contra el $\mathrm{VIH} /$ sida por parte del Ministerio de Salud, o que incluiría la provisión de medicamentos y análisis correspondientes, según lo dispuesto por los médicos del hospital tratante [...] y bajo su responsabilidad. A su vez, el Tribunal exhorta a los poderes públicos a que cumplan con lo dispuesto en el artículo 8 de la Ley 26626. Debe considerarse como inversión prioritaria el presupuesto para la ejecución del Plan de Lucha contra el sida. Ordena que la dirección del hospital tratante dé cuenta a este Tribunal, cada seis meses, de la forma como viene realizándose el tratamiento del recurrente.

En la misma resolución, el Tribunal argumentó que la “undécima disposición final y transitoria de nuestra Constitución es concordante con el artículo 2.1 del Pacto de Derechos Económicos, Sociales y Culturales, que precisa que los 
Estados se comprometen a adoptar medidas hasta el máximo de recursos que se dispongan para lograr, progresivamente, la plena efectividad de los derechos reconocidos en el Pacto, entre ellos el derecho a la salud.

Es evidente que el Estado peruano no puede eximirse de esta obligación, ni tampoco asumirla como un ideal de gestión, pues se trata de una obligación perentoria para cumplirse, si bien de manera progresiva, siempre en plazos razonables y acompañados de acciones concretas"; más adelante, el máximo intérprete de los derechos sostuvo que si bien es cierto que "en el caso de países en desarrollo, como el nuestro, resulta difícil exigir una atención y ejecución inmediata de las políticas sociales para la totalidad de la población, este Tribunal reitera que tal justificación es válida sólo cuando se observen concretas acciones del Estado para el logro de resultados; de lo contrario, esta falta de atención acarrearía situaciones de inconstitucionalidad por omisión". ${ }^{53}$

De igual manera, señaló que si bien es cierto que la efectividad de los derechos sociales "requiere un mínimo de actuación positiva del Estado a través de la adopción de medidas adecuadas para el logro de los fines sociales y del establecimiento de servicios públicos, así como de la sociedad mediante la contribución de impuestos, ya que toda política social necesita de una ejecución presupuestal, también lo es que estos derivan en obligaciones concretas por cumplir, por lo que los Estados deben adoptar medidas constantes y eficaces para lograr progresivamente su plena efectividad en igualdad de condiciones para la totalidad de la población. Esta nueva visión de los derechos sociales permite reconocer, en su contenido esencial, principios como la solidaridad y el respeto a la dignidad de la persona, los cuales, a su vez, constituyen pilares fundamentales del Estado social y democrático de Derecho". ${ }^{54}$

\section{Conclusiones}

Luego de haber realizado un breve estudio acerca de la influencia e importancia del reconocimiento de derechos sociales en la Constitución mexicana de 1917 y de su influencia en el orden jurídico peruano, podemos arribar a las siguientes conclusiones.

En primer lugar, debemos reconocer la importancia de la Constitución de 1917 para el constitucionalismo social, pues significó la primera proclamación de derechos sociales con un fundamento distinto a la mentalidad liberal que dio origen al mismo. El Ejecutivo pasó de ser el poder más temido a ser el poder más necesitado.

\footnotetext{
${ }^{53}$ Cfr. STC Nro. 2016.2004-AA/TC (Fundamentos jurídicos 36 y 38).

${ }^{54}$ Cfr. Exp. Nro.10063-2006-AA (Fundamentos jurídicos 7 y 8).
} 
En segundo lugar, debemos afirmar que el constituyente mexicano recoge inicialmente los derechos sociales con la finalidad de legitimarse y reconocer grupos vulnerables de la sociedad. Ello marca una nueva etapa en el movimiento constitucional que resulta como punto de partida para la consolidación del Estado Social y de las nuevas funciones que él conlleva para el Estado.

En tercer lugar, el constitucionalismo social mexicano influye en todas las Constituciones occidentales del mundo, en especial las de Latinoamérica. Su consolidación y su gran difusión, no obstante, no llegaron sino hasta después de la Segunda Guerra Mundial. Con ello, se dio el reconocimiento de nuevos derechos sociales distintos a los de naturaleza laboral.

En cuarto lugar, los derechos sociales implican actuación positiva del Estado y hoy en día se constituyen en muchos ordenamientos jurídicos como verdaderos derechos fundamentales, pese a que su justiciabilidad sigue siendo su gran crítica.

Finalmente, la Constitución peruana de 1920 es la primera en recoger derechos sociales y su justiciabilidad es aún compleja, debido a la cláusula de progresividad recogida en la constitución peruana vigente de 1993. El Tribunal Constitucional peruano ha reconocido la importancia de su realización progresiva, lo cual resulta una obligación real de cumplimiento por parte de todos los poderes públicos.

\section{Bibliografía}

Abendroth, Wolfgang, Forsthoff, Ernst y Dohering, Karl, El Estado Social, Madrid, Centro de Estudios Constitucionales, Madrid, 1986.

AleXY, RoBert, Teoría de los derechos fundamentales, Madrid, Centro de estudios políticos y constitucionales, 2007.

Aragón Reyes, Manuel, “Artículo 1”, en María Emilia Casas Baamonde y Miguel

Rodríguez-Piñero y Bravo Ferrer (Dirs.), Comentarios a la Constitución Española, Madrid, Fundación Wolters Kluwer, 2008.

Aragón Reyes, Manuel, Estudios de Derecho Constitucional, Madrid, Centro de Estudios Políticos y Constitucionales, Madrid, 2009.

Carpizo, Jorge y Carbonell, Miguel, Derecho Constitucional, enciclopedia jurídica mexicana, tomo 8, México, Porrúa - unam, 2002.

Carmona Cuenca, Encarnación, El Estado Social de Derecho en la Constitución, Madrid, Consejo Económico y Social, Madrid, 2000.

Cossío Díaz, José Ramón, Estado social y derechos de prestación, Madrid, Centro de Estudios Constitucionales, 1989.

Cossío Díaz, José Ramón, "Los derechos sociales como normas programáticas y la comprensión política de la Constitución”, en Ochenta años de vida constitucional en México, México, unAm, Instituto de Investigaciones Jurídicas, 1998. 
Cruz Parcero, Juan Antonio, "Los derechos sociales como técnica de protección jurídica” en Miguel Carbonell (Comp.), Derechos sociales y derechos de las minorías, México, Instituto de Investigaciones Jurídicas, México, 2000.

DíAz, Elías, Estado de Derecho y sociedad democrática, España, Taurus, 1998. Díez Picazo, Luis María, Sistema de derechos fundamentales, Navarra, ThomsonCivitas, 2008.

Fernández López, María Fernanda, “Artículo 9.2. La igualdad real” en María Emilia Casas Baamonde, y Miguel Rodríguez-Piñero y Bravo Ferrer, (Dirs.), Comentarios a la Constitución Española, Madrid, Fundación Wolters Kluwer, 2008. García de Enterría, EduARDo, "La Constitución como norma jurídica”, Revista de Administración Pública, No. 100-102, pp. 394-395.

García Pelayo, Manuel, Las transformaciones del Estado contemporáneo, Madrid, Alianza, 1977.

Garrido Falla, Fernando, Comentarios a la Constitución, Madrid, Civitas, 1980. Garrorena Morales, Ángel, El Estado español como Estado Social y Democrático de Derecho, Universidad de Murcia, Murcia, 1980.

Hakansson Nieto, Carlos, "Los derechos sociales en la constitución peruana. Elementos para una aproximación al reconocimiento y vigencia de los derechos sociales en el marco iberoamericano", Persona y derecho: revista de fundamentación de las instituciones jurídicas y de derechos humanos, No. 66-67, 2012.

Lucas Verdú, Pablo, La lucha por el Estado de Derecho, Bolonia, Publicaciones del Real Colegio de España, 1975.

Ochando Claramunt, Carlos, El Estado del bienestar. Objetivos, métodos y teorías explicativas, Barcelona, Ariel, 1999.

Parejo Alfonso, Luciano, Estado Social y Administración Pública, Madrid, Civitas, 1983.

PÉREz Royo, JAVIER, “Estado Social de Derecho” en Manuel Aragón Reyes (Dir.), Temas básicos de Derecho Constitucional, tomo I, Madrid, Civitas - Thomson Reuters, 2011.

Porras Ramírez, José María, "Caracterización y garantía de los derechos de prestación en el Estado constitucional” en Francisco Balaguer Callejón, (Coord.), Derecho Constitucional y Cultura. Estudios en homenaje a Peter Häberle, Madrid, Tecnos, 2004.

PRIETo SAnchís, LuIs, "Los derechos sociales y el principio de igualdad material”, Revista del centro de estudios constitucionales, No. 22, septiembre-diciembre, 1995. Sotelo, Ignacio, El Estado Social: antecedentes, origen, desarrollo y declive, Madrid, Trotta, Fundación Alfonso Martín Escudero, 2010.

Trujillo Pérez, Isabel, "La discutida juridicidad de los derechos sociales", Persona y Derecho, No. 45, Universidad de Navarra, 2001. 